\title{
Differentiating successful and failed molluscan invaders in estuarine ecosystems
}

\author{
A. Whitman Miller ${ }^{1, *}$, Gregory M. Ruiz ${ }^{1}$, Mark S. Minton ${ }^{1}$, Richard F. Ambrose ${ }^{2}$ \\ ${ }^{1}$ Smithsonian Environmental Research Center, PO Box 28, Edgewater, Maryland 21037, USA \\ ${ }^{2}$ Environmental Science and Engineering Program, Box 951772, University of California, Los Angeles, California 90095, USA
}

\begin{abstract}
Despite mounting evidence of invasive species' impacts on the environment and society, our ability to predict invasion establishment, spread, and impact are inadequate. Efforts to explain and predict invasion outcomes have been limited primarily to terrestrial and freshwater ecosystems. Invasions are also common in coastal marine ecosystems, yet to date predictive marine invasion models are absent. Here we present a model based on biological attributes associated with invasion success (establishment) of marine molluscs that compares successful and failed invasions from a group of 93 species introduced to San Francisco Bay (SFB) in association with commercial oyster transfers from eastern North America (ca. 1869 to 1940). A multiple logistic regression model correctly classified $83 \%$ of successful and $80 \%$ of failed invaders according to their source region abundance at the time of oyster transfers, tolerance of low salinity, and developmental mode. We tested the generality of the SFB invasion model by applying it to 3 coastal locations ( 2 in North America and 1 in Europe) that received oyster transfers from the same source and during the same time as SFB. The model correctly predicted 100,75 , and $86 \%$ of successful invaders in these locations, indicating that abundance, environmental tolerance (ability to withstand low salinity), and developmental mode not only explain patterns of invasion success in SFB, but more importantly, predict invasion success in geographically disparate marine ecosystems. Finally, we demonstrate that the proportion of marine molluscs that succeeded in the latter stages of invasion (i.e. that establish self-sustaining populations, spread and become pests) is much greater than has been previously predicted or shown for other animals and plants.
\end{abstract}

KEY WORDS: Invasion · Bivalve $\cdot$ Gastropod $\cdot$ Mollusc $\cdot$ Marine $\cdot$ Oyster $\cdot$ Vector $\cdot$ Risk assessment

\section{INTRODUCTION}

Biological invasions are a major force of ecological change, and the extent and impacts of invasions have increased dramatically in recent times (Mack et al. 2000, Pimentel et al. 2000, Carlton 2001, Grosholz 2002). Despite a general understanding of factors that influence invasion dynamics, the ability to discriminate among successful and failed invaders along biological lines, let alone predict which species become established, remains poorly developed (Williamson 1999, Ruiz \& Hewitt 2003). To date, the few quantitative efforts to predict establishment have been limited to terrestrial (Rejmánek \& Richardson 1996, Reichard \& Hamilton 1997) and freshwater (Kolar \& Lodge 2002,
Ruesink 2005) ecosystems. Such investigations have typically used statistical models to compare biological attributes of successful and failed invaders; however, while such models have explained significant amounts of observed variation in establishment and spread, and thus generated predictions, these predictions largely await independent testing to evaluate their generality (Simberloff 2001, Ruiz \& Carlton 2003). Quantitative invasion models for marine ecosystems, of the type we introduce in the present study, have been conspicuously absent in the past.

Invasions are common in coastal marine ecosystems, especially bays and estuaries (Ruiz et al. 2000). An important vector of marine and estuarine invaders has been the intentional transplantation of live oys- 
ters. The deliberate transplantation of oysters over a period of centuries has resulted in the accidental transfer and worldwide introduction of numerous associated species (i.e. occurring within or among oysters) (Elton 1958, Carlton 1992, Cohen \& Carlton 1995, Ruiz et al. 2000). Oyster-mediated invasions are well suited to the development and testing of quantitative predictions of invasion success, because they allow the comparison of successful and failed invaders from a well-defined species pool. The transcontinental shipment and introduction of live oysters Crassostrea virginica from the Atlantic coast to the Pacific coast enabled us to postulate a species pool of potential molluscan invaders that would have been dredged with oysters prior to commercial transport. Furthermore, because oyster were repeatedly taken from the same locations on the east coast and independently introduced to geographically disparate locations (Miller 2000), we had the opportunity to test whether model results from one invasion location predicted those observed elsewhere.

We compared species attributes of successful and failed invaders in San Francisco Bay (SFB) California, USA, associated with transfers of the eastern oyster Crassostrea virginica, originating from a specific source region in eastern North America (Miller 2000). From 1869 to 1940, billions of live oysters were dredged from the marine and estuarine waters surrounding New York City and transported, live, in wooden barrels either by rail to the Pacific Coast of North America or by ship to Europe (Ingersoll 1881, Barrett 1963, Carlton 1979). These oysters were both seed oysters (to be planted for grow-out in beds of the recipient region) and adult oysters for direct sale. Both oyster types provided an opportunity for introducing nonindigenous species since market-ready oysters were commonly stored in recipient waters prior to sale (Miller 2000). Peak rates of oyster transfer occurred between the 1870s and 1910 (Barrett 1963). The unusually high quality of existing historical data on the species composition of oyster beds, for this specific time period and source region, allowed us to characterize the available pool of species associated with oysters that were captured in dredges as by-catch and transferred across the continent. We focused our analysis on marine molluscs because data are most comprehensive and reliable for this taxonomic group, due to the widespread and long-time interest in the group both among professional scientists and amateur shell collectors.

We constructed a multiple logistic regression model to quantitatively differentiate successful and failed molluscan invaders of SFB according to their underlying biology as a means for explaining the observed invasion pattern. The model assigned probabilities to individual species to assess the likelihood ('relative risk') that each species would successfully invade. To assess the predictive power of the SFB model, it was applied to 3 geographically separated estuaries: Willapa Bay and Puget Sound, Washington, USA, and Essex County, England, to determine how well it identified invaders in these locations. These estuarine systems shared the same source (waters surrounding New York City and Long Island), vector (live oyster transfers), and timing of introductions (late 19th and early 20th centuries).

In an attempt to understand whether the SFB model assigned significantly higher risk values to species that have invaded multiple locations (i.e. 'repeat invaders') than to other species in the pool, the repeat invader mean probability was compared to mean probabilities derived from similarly sized, but randomly assembled, species groups through bootstrap analysis. Finally, to investigate whether species occurrences across locations deviated from random, a numerical experiment was performed.

\section{MATERIALS AND METHODS}

The species pool of potential invaders was compiled by identifying all bivalve and gastropod molluscs that were associated with the oyster Crassostrea virginica from the mid Atlantic region of the United States, according to historical records and the scientific literature. We included species that would have been collected as by-catch in oyster dredges (i.e. molluscs occurring naturally in and around oyster beds) and species that likely colonized oysters while they were stored at the water's edge prior to shipment (Carlton 1979, Miller 2000). Molluscan species were only included in the species pool if (1) there was strong evidence that they occur directly with, or in close proximity to, oysters in the wild; (2) they had the capacity to colonize harvested oysters and associated equipment prior to shipment (and if this was likely); or (3) they were documented directly in barrels of live oysters collected for transport (e.g. Winkley 1888). For each species, information on 19 biological attributes was compiled through a literature review. No a priori criteria were used to identify specific biological attributes; instead, attributes were selected according to their availability in the literature and to their application to the broadest set of species. These data were composed of categorical, ranked, and continuous data types (Table 1). All categorical data were dummy coded prior to statistical analyses. Details on specific methods used for all categorical, ranked, and continuous variables are available electronically (see Appendix 1, available as Supplementary Material at www.int-res.com/ articles/suppl/m332p041_app1.pdf). 
Table 1. Biological attributes, measures, and data types investigated with the logistic regression model of invasion probability. Attributes in bold were incorporated in the final model. For detailed descriptions of attributes see Appendix 1, available at www.int-res.com/articles/suppl/m332p041_app1.pdf

\begin{tabular}{|c|c|c|}
\hline Biological attribute & Unit of measure or condition & Data type \\
\hline Amphi-Atlantic distribution & (Yes/no) & Categorical \\
\hline Native faunal group ${ }^{\mathbf{a}}$ & Northern, Northern TransHatteran, Southern TransHatteran & Categorical - nominal \\
\hline Northern limit & Degrees $\left({ }^{\circ}\right)$ & Continuous \\
\hline Southern limit & Degrees $\left({ }^{\circ}\right)$ & Continuous \\
\hline Latitudinal range & Degrees $\left({ }^{\circ}\right)$ & Continuous \\
\hline Salinity zone & $\begin{array}{l}\text { Stenohaline-estuarine }{ }^{\mathrm{b}} \text {, euryhaline-estuarine }{ }^{\mathrm{c}}{ } \\
\text { stenohaline-marine }^{\mathrm{d}}{ }^{\text {, euryhaline-marine }} \mathrm{e}^{\mathrm{e}}\end{array}$ & Categorical - nominal \\
\hline Low salinity distribution & $(\%)$ & Continuous \\
\hline High salinity distribution & $(\%)$ & Continuous \\
\hline Salinity range & $(\%)$ & Continuous \\
\hline Substrate preferences & Hard, soft, both & Categorical - nominal \\
\hline Benthic placement & Infaunal, epifaunal & Categorical - nominal \\
\hline Habitat diversity & $1-6$ & Discrete - rank \\
\hline Tidal height location & Subtidal, intertidal, both & Categorical - nominal \\
\hline Maximum depth & $(\mathrm{m})$ & Continuous \\
\hline Depth diversity & $1-4$ & Discrete - rank \\
\hline Developmental mode & Planktonic, direct & Categorical \\
\hline Feeding mode & $\begin{array}{l}\text { Suspension, deposit, predator, herbivore, omnivore, } \\
\text { scavenger/detritivore }\end{array}$ & Categorical - nominal \\
\hline Maximum adult shell length & (1) & Continuous \\
\hline Historical abundance & $0-10$ & Averaged rank \\
\hline \multicolumn{3}{|c|}{$\begin{array}{l}\text { aSpecies ranging to the north and south of Cape Hatteras are considered TransHatteran. Species ranging to the north of Cape } \\
\text { Cod are considered Northern or Northern TransHatteran, and species that do not occur north of Cape Cod are considered } \\
\text { Southern TransHatteran } \\
\text { bSalinity range spanning } 15 \% \text { or less, but confined to estuarine conditions } \\
\text { 'Salinity range spanning } 16 \% \text { or more, but confined to estuarine conditions } \\
\text { dSalinity range spanning } 15 \% \text { or less and including marine conditions of } 32 \% \text { or more } \\
\text { e'Salinity range spanning } 16 \% \text { or more, including marine conditions }\end{array}$} \\
\hline
\end{tabular}

SFB invasion model. Potential invaders were assigned to 2 categories: (1) SFB invaders (i.e. selfsustaining non-native populations), and (2) failed invaders. SFB-invader status was based on the findings of previously published studies (Carlton 1979, Cohen \& Carlton 1995). A multiple logistic regression analysis (performed with SAS OnlineDoc ${ }^{\circledR}$ 9.1.2; SAS 2000) was used to identify those attributes with the greatest power to accurately differentiate successful from failed invaders. Because logistic regression can incorporate dummy coded categorical data and ordinal data, as well as continuous data, and is not constrained by unequal variances and deviations from normality, it is also well suited for modelling dichotomous outcomes (Agresti 2002); in this case, invasion success and failure.

The general logistic regression model is:

$$
\pi(x)=\frac{\exp (\alpha+\beta x)}{1+\exp (\alpha+\beta x)}
$$

where $\pi(x)$ is the probability of success for a given observation $x$, while $\alpha$ and $\beta$ are analogous to the intercept and slopes in linear regression, respectively.

To identify those parameters that provided the greatest explanatory power, we applied a variety of model selection techniques using Proc Logistic (SAS v9.1;
SAS 2000). Based on parameter estimates, the odds ratios indicate the percent change in the odds of invasion with unit increases to each of a model's independent predictor values. Odds are the probability of success divided by the probability of failure and the odds ratio is the proportional change in odds with a unit change of the independent variable (i.e. unit change to the predictor). Beginning with automated techniques (Buchan \& Padilla 2000, Agresti 2002, Frappier \& Eckert 2003, Hurme et al. 2005), we conducted forward selection $(P$-to-enter $=0.2)$, backward selection $(P$-toremove $=0.1)$, forward stepwise $(P$-to-enter $=0.2$ and $P$-to-remove $=0.1$, and the best subset algorithm (score chi-square statistic). Both forward techniques and the best subset algorithm identified a similar group of predictor variables; however, the backward selection did not differentiate variables well and yielded a model that incorporated nearly all possible predictors. Due to the inclusion of categorical variables and the existence of some multicollinearity among variables, we manually removed predictors from the saturated model based on changes in the log-likelihood and the Akaike's information criterion (AIC) to identify the most parsimonious model (Agresti 2002). A deviance goodness of fit test indicated that the logistic regression model was appropriately fitted to the data 
set. The model's explanatory power is summarized according to the ability of the logistic regression to correctly categorize successful invaders (the model's sensitivity) and failed invaders (specificity) of SFB. These measures of predictive power are directly dependent upon the cut-off criterion value that delineates successful invasion from failed invasion (Fielding \& Bell 1997). The model's invasion success probability criterion cut-off was set where sensitivity and specificity were maximized (Hurme et al. 2005).

Gastropods and bivalve models. Molluscs were divided along taxonomic lines (i.e. gastropods and bivalves) to determine whether the explanatory parameters in the mollusc model contributed differentially to the gastropod and bivalve models.

Tests of SFB model predictive power. To test the predictive power of the SFB mollusc invasion model, it was applied to 3 additional invasion sites where eastern oysters were transplanted from the same source region and during the same time period as those sent to SFB (Miller 2000). These tests were made for Willapa Bay (WB) and Puget Sound (PS), Washington, USA (Carlton 1979), and Essex County (EC), England (Eno et al. 1997). Percent correct classification by the SFB model for the 7 successful invaders was determined within and across locations.

Repeat invaders. Mean invasion probability of repeat invaders: A bootstrap analysis was used to determine whether the mean modelled invasion probability of the group of 7 repeat invaders (Crepidula plana, C. fornicata, Myosotella myosotis, Ilyanassa obsoleta, Urosalpinx cinerea, Mya arenaria, and Petricolaria pholadiformis) was greater than that of the entire species pool mean, as estimated by multiple randomly selected 7 -species samples. We selected random 7-species combinations, with replacement (10000 iterations), from the pool of 93 potential invaders to generate a bootstrap sample frequency distribution of mean invasion probabilities. The mean invasion probability of the 7 repeat invaders was then compared with the upper extreme of the bootstrap distribution.

Are invasion patterns random? To formally estimate the likelihood of multiple random invasions by the same organisms in different geographic locations, we employed a numerical experiment that examined the individual and joint probabilities of obtaining invaders that were also shared with SFB. We asked: 'When all invaders arise from the same species pool $(\mathrm{n}=93)$, what is the probability that the invader species in a non-SFB location are the same as those in SFB?' Modelling multiple invasions from a single species pool assumed: (1) that there were independent introductions of the same 93 species to multiple locations; (2) that one invasion did not influence another, either in the same or a different geographic area; (3) that all species in all environments share equal invasion probabilities. Note, after Mya arenaria's accidental invasion of SFB it became an important commercial shellfish and was subsequently intentionally introduced to WB (before 1884) and then from WB to PS (1888-1889) (Carlton 1979). Whether or not $M$. arenaria was already established prior to these early plantings is not known. For these reasons, M. arenaria was excluded from this analysis.

To estimate the likelihood of similar species invading SFB and another location by chance alone, we used a mathematical combinations approach where combinations were same-sized groups with unique membership (Anderson et al. 1994). For these analyses, we recognized the following species as ones that were shared with SFB: WB $(\mathrm{n}=5$, Crepidula plana, Myosotella myosotis, Ilyanassa obsoleta, Urosalpinx cinerea, Petricolaria pholadiformis), Puget Sound $(\mathrm{n}=3$, C. plana, $M$. myosotis, $U$. cinerea) and EC $(\mathrm{n}=2, U$. cinerea and $P$. pholadiformis). Using combinatorial mathematics (Anderson et al. 1994; Appendix 1), we first calculated the total possible unique combinations $(C)$ of 11 species $(11=$ number of SFB invaders, minus Mya arenaria) that could be taken from a pool of 92 species (93 minus $M$. arenaria):

$$
C(92,11)=\frac{(92 !)}{[11 !(92-11) !]}
$$

To determine the number of 11 species combinations that also included repeat invaders to EC, PS, and WB, we employed Eq. (3), where $r p=$ the number of repeat invaders for each location:

$$
C(92-r p, 11-r p)=\frac{(92-r p) !}{\{(11-r p) ![(92-r p)-(11-r p)] !\}}
$$

Thus, for each location the probability of observing the patterns of repeat invasions by chance alone was calculated as the quotient, Eq. (3)/Eq. (2). A joint probability describing the probability of observing the repeat invasions across all locations was calculated as the product of the 3 site-specific probabilities.

\section{RESULTS}

\section{SFB invasion model}

The multiple logistic regression recognized 3 of 19 species' attributes (Table 1) (historical abundance in the source region, tolerance of low salinity, and developmental mode) as important for differentiating successful molluscan invaders from failed invaders in SFB. Of these, direct development was shared among 5 of 
the $12(42 \%)$ successful invaders: Crepidula convexa, Busycotypus canaliculatus, Myosotella myosotis, Urosalpinx cinerea, and Gemma gemma (see Appendix 2, available as Supplementary Material at www.intres.com/articles/suppl/m332p041_app2.pdf). Among all species, 16 of $93(17 \%)$ were direct developers. Ten of the 12 invaders (83\%) were ranked among the 23 most historically abundant molluscan species associated with oysters (see Appendix 2). The snails Boonea bisuturalis and $M$. myosotis, the other 2 successful invaders, were ranked 33rd and 43rd in their historical abundance among the species examined. With respect to salinity tolerance, 8 of 12 species $(75 \%)$ have been recorded naturally in habitats of $12 \%$ or less, but 4 successful invaders are found in slightly higher salinities (15 to $18 \%$ ).

Multiple logistic regression analysis identified 3 attributes that together best differentiated between successful and failed invaders among molluscs introduced to SFB with commercial oysters. The independent predictors included historical abundance in the source region, developmental mode, and tolerance of low salinity (Appendix 2). The probability of invasion, $P(I)$, based on the output of the multiple logistic regression was calculated as follows:

$P(I)=$

$\exp [-3.6084+0.5605(H A)+1.3207(D M)-0.1090(L S)]$

$\overline{1+\exp [-3.6084+0.5605(H A)+1.3207(D M)-0.1090(L S)]}$

where $H A$ is the historical abundance, $D M$ is the developmental mode, and $L S$ is the low salinity tolerance. The global likelihood ratio test indicated that the model was significant $\left(\chi^{2}=25.14\right.$, df $\left.=3, p<0.0001\right)$, indicating that further interpretation of the model parameters was statistically justified. A deviance chisquare test indicated that the model was well-fitted to the data set $\left(D_{\mathrm{m}}=44.37, \mathrm{df}=75, \mathrm{p}=0.9981\right)$, where $D_{\mathrm{m}}$ is the model deviance. The model's predictive power, as measured by the concordance index $(c)$, was quite high, $c=0.914$. The concordance index estimates the probability that predictions agree with observed outcomes, thus when $c=0.5$, predictions are the same as would be expected by random chance (Agresti 2002). The odds ratios, $\exp (\beta)$, are reported with the Wald's $95 \%$ CI for each predictor as follows: historical abundance $\exp (0.5567)=1.745$ (1.185 to 2.568$)$, developmental mode $\exp (1.3265)=3.768(0.729$ to 19.475$)$, low salinity tolerance $\exp (-0.1084)=0.897(0.797$ to 1.010$)$. These results indicate that for each unit increase in historical abundance (range $=0$ to 10), the odds of invasion increased by $74.5 \%$. Therefore, all other things equal, when comparing a species with an historical abundance of 0 to a species with an historical abundance of 10 , the odds ratio is $\exp (10 \times 0.5567)=$ 261.6, indicating a $>260$-fold increase in the odds of invasion for the most abundant species. Similarly, for developmental mode (condition $=1$ or 0 ) direct development increased invasion likelihood by $>3$-fold. Finally, species which are able to withstand lower salinities had increased probabilities of invasion. This invasion probability increased at a rate of $11.4 \%$ per unit decrease in concentration (range 31-0\%) or over 28 -fold across the entire range. Given the respective odds ratios and dynamic ranges of these predictors, historical abundance had the greatest capacity to influence the model's estimate of invasion probability, followed by tolerance of low salinity, and developmental mode.

Of the 86 species for which abundance, developmental mode, and salinity data were available, the logistic regression correctly classified $83.3 \%$ of successful invaders (10 of 12 species) and $79.7 \%$ of failed invaders (59 of 74 species). Overall, the model correctly classified $80.2 \%$ of species, indicating high model accuracy (sensu Smith et al. 1999) (Fig. 1a). The model's explanatory power is summarized according to the logistic regression classification table which quantifies its ability to correctly categorize successful invaders (the model's sensitivity) and failed invaders (specificity) of SFB. The model's invasion success probability criterion cut-off was set where sensitivity and specificity were maximized $(P(I)=0.18$, Fig. 1b). Under this condition, the model did not correctly classify successful invasion by either the bivalve Petricolaria pholadiformis or the snail Boonea bisuturalis, but correctly classified all other actual invaders.

\section{Gastropod and bivalve models}

When the same 3 model parameters were examined for gastropods and bivalves separately, historical abundance was shown to be the most important predictor in both models. Among gastropods, developmental mode was also important for discriminating among successful and failed invaders, but tolerance of low salinity was not. Probability of gastropod invasion was estimated as:

$$
P(I)=\frac{\exp [-4.7089+0.5064(H A)+1.1741(D M)]}{1+\exp [-4.7089+0.5064(H A)+1.1741(D M)]}
$$

The parameters were significantly different from zero $\left(\chi^{2}=10.80, \mathrm{df}=2, \mathrm{p}=0.0045\right)$ and the model fitted the data $\left(D_{\mathrm{m}}=29.08, \mathrm{df}=38, \mathrm{p}=0.8504\right)$. The model's predictive power was high $(c=0.864)$.

For bivalves, tolerance of low salinity proved more critical than developmental mode for predicting invasion success. Probability of bivalve invasion was estimated as: 

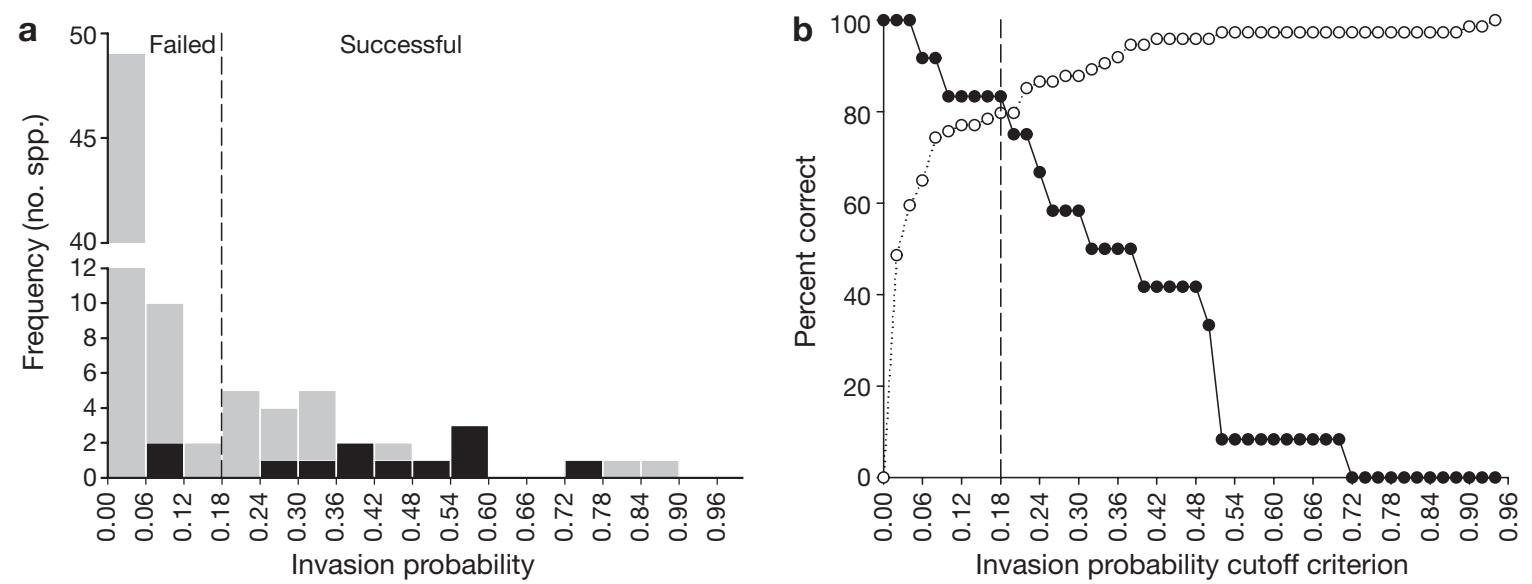

Fig. 1. (a) Frequency distribution of western Atlantic molluscan oyster-associates by invasion probability as modelled with logistic regression. The species pool $(n=86)$ includes species introduced to San Francisco Bay $(\mathrm{SFB})$ with commercial oyster transplants. Shading indicates actual invasion status in SFB. Black bars: successful invaders of SFB $(n=12)$; gray bars: failed invaders of SFB $(\mathrm{n}=74)$. Predicted invasion probabilities were calculated using Eq. (4) (see 'SFB invasion model' in 'Results') and invasion success probability criterion cut-off was set at 0.18 (dashed line) indicating the probability at which the model correctly categorizes the most successful and failed invasions. (b) SFB model sensitivity (i.e. number of correctly categorized successful invaders; solid circles) and specificity (i.e. number of correctly categorized failed invaders; open circles) as each varies with invasion probability criterion cut-off choice. A criterion cut-off was chosen as the point where sensitivity and specificity are maximized ( $p=0.18)$

$P(I)=\frac{\exp [-2.7149+0.7036(H A)-0.2786(L S)]}{1+\exp [-2.7149+0.7036(H A)+0.2786(L S)]}$

Again, parameters deviated significantly from zero $\left(\chi^{2}=16.36, \mathrm{df}=2, \mathrm{p}=0.0003\right)$. The data fit the model well $\left(D_{\mathrm{m}}=14.30, \mathrm{df}=35, \mathrm{p}=0.9993\right)$ and the predictive power of the model was very high $(c=0.941)$.

\section{Tests of SFB model predictive power}

Seven molluscs from the initial species pool established self-sustaining populations among the other 3 sites (Table 2). The model correctly predicted $85.7 \%$ (6 out of 7) successful invaders in WB, $100 \%$ (5 out of 5) in PS, and $75 \%$ (3 out of 4 ) in EC. Overall, 85.7\% (6 out of 7) of successful oyster-mediated invasions were predicted by the SFB model.

\section{Repeat invaders}

Mean invasion probability of repeat invaders

To determine how the group of repeat invaders compared biologically to similar sized groups taken from the entire species pool, a re-sampling experiment was performed, using bootstrap analysis. The mean invasion probabilities calculated by the logistic regression model for 7 repeat invaders of SFB, WB, PS, or EC were averaged and compared to randomly selected, likesized group means. The mean invasion probability for repeat invaders fell in the extreme upper range of bootstrap distribution (99.6th percentile, Fig. 2), indicating a markedly higher mean invasion probability for repeat invaders than expected by chance alone $(\mathrm{n}=$ 7 spp. and 10000 iterations). A similar result was obtained if Mya arenaria was removed from the analysis due to possible enhanced propagule pressure from intentional introduction ( $\mathrm{n}=6 \mathrm{spp}$; mean invasion probability $=0.3543,98.7$ th percentile).

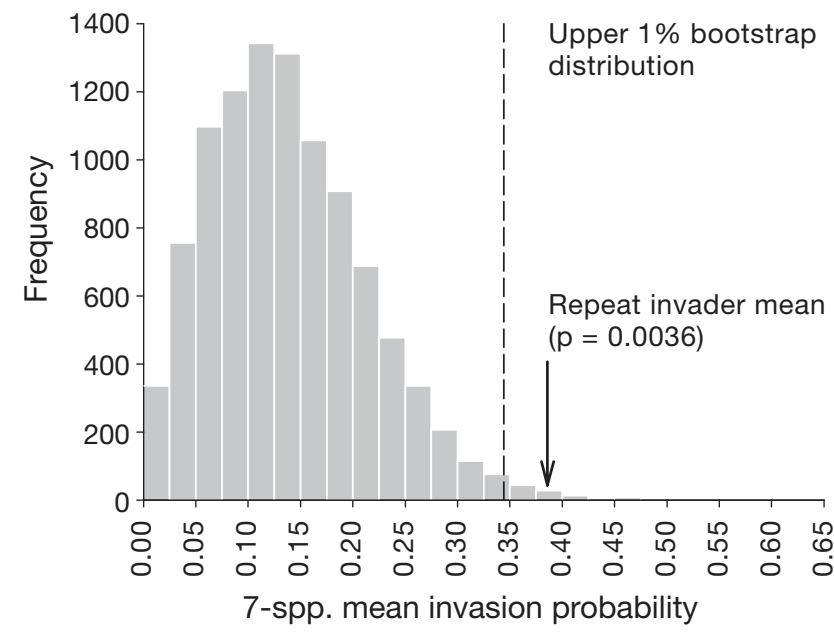

Fig. 2. Bootstrap analysis comparing mean invasion probability value of 7 repeat invaders (arrow) with like-sized species groups. Groups of species were resampled with replacement and means reported for 10000 iterations. Repeat invaders have higher invasion probabilities than expected by chance alone $($ mean $=0.3861, p=0.0036)$. Dashed line: upper $1 \%$ range of the distribution 
Table 2. Western Atlantic molluscan invaders of 4 estuarine ecosystems and their corresponding invasion probabilities, as modelled by multiple logistic regression for San Francisco Bay, CA, USA

\begin{tabular}{|c|c|c|c|c|c|}
\hline Species & $\begin{array}{l}\text { San } \\
\text { Francisco } \\
\text { Bay, CA }\end{array}$ & $\begin{array}{l}\text { Willapa } \\
\text { Bay, } \\
\text { WA }\end{array}$ & $\begin{array}{l}\text { Puget } \\
\text { Sound, } \\
\text { WA }\end{array}$ & $\begin{array}{l}\text { Essex } \\
\text { County } \\
\text { coast, UK }\end{array}$ & $\begin{array}{l}\text { Invasion } \\
\text { probability }\end{array}$ \\
\hline Boonea bisuturalis & $\mathrm{X}$ & & & & $0.062^{\mathrm{b}}$ \\
\hline Busycotypus canaliculatus & $\mathrm{X}$ & & & & 0.419 \\
\hline Crepidula convexa & $\mathrm{X}$ & & & & 0.580 \\
\hline Crepidula plana & $\mathrm{X}$ & $\mathrm{X}$ & $\mathrm{X}$ & & 0.281 \\
\hline Crepidula fornicata & & $\mathrm{X}$ & $\mathrm{X}$ & $\mathrm{X}$ & 0.340 \\
\hline Myosotella myosotis & $\mathrm{X}$ & $\mathrm{X}$ & $\mathrm{X}$ & & 0.393 \\
\hline Ilyanassa obsoleta & $\mathrm{X}$ & $\mathrm{X}$ & & & 0.540 \\
\hline Urosalpinx cinerea & $\mathrm{X}$ & $\mathrm{X}$ & $\mathrm{X}$ & $\mathrm{X}$ & 0.469 \\
\hline Gemma gemma & $\mathrm{X}$ & & & & 0.747 \\
\hline Geukensia demissa & $\mathrm{X}$ & & & & 0.577 \\
\hline Macoma balthica & $\mathrm{X}$ & & & & 0.310 \\
\hline Mya arenaria & $\mathrm{X}$ & $\mathrm{X}^{\mathrm{a}}$ & $\mathrm{X}^{\mathrm{a}}$ & $\mathrm{X}^{\mathrm{a}}$ & 0.577 \\
\hline Petricolaria pholadiformis & $\mathrm{X}$ & $\mathrm{X}$ & & $\mathrm{X}$ & $0.103^{\mathrm{b}}$ \\
\hline \multicolumn{6}{|c|}{$\begin{array}{l}{ }^{a} \text { Locations where Mya arenaria was intentionally transplanted as well as } \\
\text { accidentally introduced. Invasion probabilities are those derived from the SFB } \\
\text { multiple logistic regression model, summarized in Fig. } 1 \\
\text { b Species misclassified by the SFB logistic regression model }\end{array}$} \\
\hline
\end{tabular}

spread (Ruiz \& Carlton 2003). The present study underscores how biological attributes of species and their populations may influence invasion success in estuaries across several of these stages.

Our analysis found that historical abundance of molluscs in the source region was the strongest predictor of their invasion success in SFB. This was true whether or not molluscs were split into gastropod and bivalve groups. Relative abundance is likely a strong proxy for propagule pressure to the receiving ecosystem for a number of reasons. First, oysters were harvested with oyster dredges, a non-selective method that results in extensive by-catch and entrainment of species. Indeed, of the more than 200 non-indigenous marine invertebrate and algal species found in $\mathrm{SFB}$, a total of 52 are western Atlantic species probably introduced with commercial oysters, making this an important vector for all non-native biota there (Carlton 1992, Cohen \& Carlton 1995). Second, the magnitude and frequency of annual live oyster shipments made for the express purpose of planting in SFB probably favoured species in proportion to their abundance. During the peak years of transcontinental live oyster transfers (1887 to 1908), shipments averaged 125 railcars per year (Carlton 1979), the equivalent of $>1.5$ million pounds $(680 \mathrm{t})$ of live oysters and associated biota per year. And third, the vast number of repeated inoculations across the $70 \mathrm{yr}$ period of practice when live eastern oysters were placed in SFB for grow-out and shortterm storage (Barrett 1963, Carlton 1979, Miller 2000) likely enhanced inoculation rates according to species abundance. Thus the average source region abundance of molluscs, when combined with the known magnitude, frequency, and duration of oyster transfers, serves as a good surrogate of propagule pressure.

More broadly, our results emphasize the fundamental importance of propagule pressure to invasion success in marine ecosystems, adding further support and generality to a conclusion drawn in terrestrial systems (Shoener \& Spiller 1995, Williamson \& Fitter 1996, Lonsdale 1999, Kolar \& Lodge 2001). Lockwood et al. (2005) indicate that when propagule pressure was accounted for in historical and experimental invasion studies, it tended to outweigh other biological predictors of invasion. Ruiz \& Carlton (2003), however, highlight the need for greater elucidation of the doseresponse relationship between propagule pressure and probability of establishment (invasion success), which

may vary among taxa and recipient environment.
Biological invasions occur when historically important geographic barriers are breached, usually in connection with human activities. The invasion process is a multistaged phenomenon that includes entrainment of organisms by a vector, survivorship during transit, initial survivorship upon release to a new environment, establishment of self-sustaining populations, and subsequent 
Two additional biological characteristics - tolerance of low salinity and developmental mode-were important for predicting invasion success of molluscs. In marine ecosystems environmental tolerance is widely viewed as limiting the distribution of organisms within their native ranges (Kennish 1990), particularly temperature and salinity tolerance. Since marine invasions are known predominantly from bays and estuaries, which often exhibit salinity fluctuations due to freshwater runoff, it is not surprising that tolerance to low salinity was associated with invasion success. Species lacking the requisite biological capacity to survive and reproduce in a new environment will fail as invaders. Indeed, environmental tolerance has been closely associated with invasion success in terrestrial systems as well (Roy et al. 1991, Goodwin et al. 1998). In our analyses, salinity tolerance, as indicated by the lowest salinity concentrations where a species naturally occurs, may represent a critical environmental barrier to survival for many members of the species pool. Nevertheless, salinity tolerance is also known to vary genotypically in marine invertebrates (Lee et al. 2003). As such, there may exist an important, but unmeasured, synergism between salinity tolerance and historical abundance, e.g. an increased probability of entrainment, transport, and introduction of the most tolerant individuals of a species could increase probability of invasion success.

Survivorship is obviously critical during transport as well as after a species is introduced to a new environment. Interestingly, while tidal height location (Table 1) was not identified in our model as a predictor of invasion success, all invaders occur in either intertidal (or intertidal and subtidal habitats), and none is confined strictly to the subtidal. This pattern may reflect the ability of these animals to better withstand desiccation, as was imposed by transcontinental and transatlantic shipment of oysters in barrels. Alternatively, desiccation could be a limiting factor to invasion success in the recipient environment, especially if oysters were bedded in intertidal habitats, as was predominantly practiced in SFB (Ingersoll 1881). While it is impossible to determine the exact role of desiccation for molluscan invasion success in SFB, the pattern points to the importance of environmental stresses at multiple stages of any given invasion pathway.

Developmental mode differentiated successful and failed invaders in SFB and predicted invasions elsewhere. In particular, the model indicated that if a mollusc was a direct developer, the odds of invasion success was approximately 3.7 times that of species with planktonic development, all other factors being equal. Developmental mode contributed more to invasion success of gastropods than bivalves. Since there was just one direct developing bivalve, Gemma gemma, the contributing statistical power of this attribute is likely low. Direct development may confer significant advantages to organisms that are transferred long distances to regions beyond their native range (Johannesson 1988). In planktonic species, Allee effects (i.e. a positive relation between population density and the per capita growth rate) may be more pronounced than in direct developers, since inoculation sizes are small and the effects of diffusion over space on larval density may be crucial, even in semi-enclosed embayments. For sedentary direct developers such as G. gemma or Urosalpinx cinerea, which bear live young or lay eggs with crawl-away juveniles, offspring will reside in the same location as their parents and siblings, thereby increasing mate availability and the likelihood of establishing a self-sustaining population (Johannesson 1988). Among the 88 species in the source applicant pool for which developmental mode information was available, $81.8 \%$ are planktonic and $18.2 \%$ are direct developers. Of the 12 SFB invaders just $58.3 \%$ are planktonic vs. $41.7 \%$ that are direct developing, demonstrating that direct developers successfully invaded far more frequently than would be expected by chance $\left(\chi^{2}=5.86, \mathrm{df}=1, \mathrm{p}=0.016\right)$ according to the proportion at which they were introduced. Once introduced, direct developers may colonize previously uninhabited regions more efficiently than planktonic species.

Analyses of successful oyster-mediated invaders across multiple locations served to test the SFB model, validating the model's predictions and also revealing that the observed invasions were clearly not random events. When the group of repeat invaders was analyzed, mean invasion probability, as estimated by the logistic regression model, was statistically higher than like-sized, randomly chosen species groups. These findings support the hypothesis that invasion success is closely correlated with particular biological attributes and propagule pressure and not an idiosyncratic, unpredictable process.

The non-random invasion patterns observed in west coast and British estuaries indicate that a small subset of species invaded repeatedly. Likewise, the majority of oyster-associated molluscs failed in all locations, despite recurring inoculations. As in SFB, the flux of eastern oysters from the Atlantic to WB $(1874 ; 1894$ to the 1920s) and PS (1870s/1880s; 1899 to the 1920s) were extensive and well documented (see Carlton 1979 and references therein), as were live shipments to England which occurred from the 1870s into the first half of the 20th century (Ingersoll 1881, Kochiss 1974). From this perspective, each estuary was inoculated numerous times over many years from the same source. Whether the invasion patterns observed in west coast estuaries are also partly the result of initial invasions to SFB followed by secondary movements of species among bays cannot be fully resolved without 
genetic analyses. Given the magnitude of oyster inoculations from the Atlantic, we suspect that opportunities for direct introduction outstripped those of along-coast species movements.

While ships did move among these estuaries, shipping vectors (i.e. hull fouling and ballast) are not cited as probable modes of molluscan introduction and transport in west coast ecosystems (Carlton 1979, 1992, Cohen \& Carlton 1995). A more plausible mode is along-coast oyster transplant, but extant records of these activities are rare. Beginning in 1905 the Morgan Co. did move an unspecified number of live Crassostrea virginica from their commercial beds in SFB to beds they owned in $\mathrm{WB}$, in response to the rapid decline, and complete failure by 1910, of oyster grounds in SFB (Barrett 1963). We were unable to find evidence of similar oyster movements from SFB to PS or WB to PS, but small, undocumented transfers cannot be ruled out. The lateness of first records for western Atlantic molluscs in WB and PS (1930s and after) are not helpful in ascertaining the species' true sources, since these may reflect search effort rather than actual invasion date. Although we cannot quantify the degree to which connectedness may have influenced the nonrandom patterns in west coast estuaries, it is instructive to note that EC, a location with no connection to the west coast of the United States, was invaded by the same species.

Our model misclassified 15 species as false-positive SFB invaders (i.e. failed invaders classified as successful); however, among these species at least $4(26.7 \%)$ have invaded other locations in the world (Crassostrea virginica, Mercenaria mercenaria, Crepidula fornicata, and Littorina saxatilis). Environmental and demographic stochasticity will always hamper the precision with which invasion success can be predicted. Thus, species which are well-suited for invasion success due to their life history, ecology, and perhaps propagule pressure, will not necessarily invade on a predictable schedule, even after repeated inoculation. From this perspective, false-positives in our model may actually represent insipient invaders which could be viewed as higher risk species. This is underscored by the recent invasion of SFB by the direct developing snail L. saxatilis, which was probably introduced with seaweed packing materials from New England some decades following the cessation of live oyster transplants (Carlton \& Cohen 1998, Miller et al. 2004). The misclassification of the invaders Boonea bisuturalis and Petricolaria pholadiformis may reflect a limitation of the biological and ecological data collected for this analysis. B. bisuturalis, a small and inconspicuous ectoparasite of oysters, likely occurs at higher densities on oyster beds than surrounding habitats. If so, its abundance may have been underestimated in 19th century bio- logical surveys, which were directed across multiple habitats, rather than at oyster reefs specifically.

The Western Atlantic molluscs included in the present study depart markedly from the 'tens' rule prediction of Williamson \& Fitter (1996). Our results indicate that the percentage of molluscan introductions that became invasive in SFB was nearly 2 orders of magnitude greater than what Williamson \& Fitter's (1996) model predicts (8.5 vs. $0.1 \%$ ). Under the tens rule, roughly $10 \%$ (estimated as 5 to $20 \%$ ) of introduced species escape cultivation and survive in the wild; $10 \%$ of escaped species establish reproducing populations; and $10 \%$ of established species become pests.

If eastern oysters are counted among the species introduced to SFB, the total species pool was 94 species (93 associates + Crassostrea virginica). Among these 94 species, $13(13.8 \%)$ survived in the wild, which conforms to Williamson \& Fitter's (1996) prediction. Nevertheless, 12 of 13 molluscan survivors (92.3\%) established reproducing populations, versus the predicted 1.3 species. Moreover, 8 of 12 established species $(67 \%)$ became pests as measured via economic impacts (Cohen \& Carlton 1995), competitive displacement (Race 1982), or by extreme abundance when compared to native fauna (Hopkins 1986), rather than 0.13 species as predicted by the tens rule.

Our findings reinforce the observations of Jeschke \& Strayer (2005) that animals can show much higher rates of establishment and spread following introduction than terrestrial plants. Jeschke \& Strayer (2005) concluded that among vertebrate introductions between North America and Europe (freshwater fishes, birds, and mammals) far more than $10 \%$ of introduced species became established and $>10 \%$ of established species became pests. These results demonstrate a remarkable convergence of invasion success rates among animals in widely divergent ecosystems, including terrestrial, freshwater, and marine systems.

To our knowledge, the present study is the first to assess quantitatively the biology of successful and failed invaders as a means for explaining and predicting marine invasion. Quantitative explanations and predictions of biological invasions have been especially elusive because key information is often unavailable to characterize the identity of failed invaders and the propagule supply of introductions, or the supply side of the invasion process. In particular, for most vectors, the inoculation attributes (e.g. identity, density and frequency of introductions) are typically unknown, precluding comparisons of successful and failed invasions. Using oyster-mediated transfers allowed us to overcome these constraints by identifying the species pool (especially failed species), while also controlling for possible confounding effects of vector, time, source region, and recipient regions. 
Despite the overall small number of empirical analyses on the factors driving invasion success, we are encouraged by the concordance of results reported for terrestrial and freshwater ecosystems and those described here for marine fauna. Clearly, more work of this kind is needed to (1) test the generality of these results across a wider range of vectors, taxonomic groups, habitat types, geographic regions, and environmental conditions; and (2) refine the quantitative relationship between inoculation attributes (i.e. dose and frequency of introduction) and invasion outcome (Ruiz \& Carlton 2003). Such work is critical to our understanding of invasion dynamics, and also to the development of effective management and policy aimed at reducing the likelihood of new invasions and their concomitant ecological, economic, and public health costs.

Acknowledgements. We thank M. Torchin, C. deRivera, P. Foffonoff, R. Osman, S. Santigata, and K. Klug for their insight and helpful comments. We also thank L. Levin, K. Wasson and 2 anonymous reviewers for their suggestions to improve the manuscript.

\section{LITERATURE CITED}

Agresti A (2002) Categorical data analysis, 2nd edn. John Wiley, Hoboken, NJ

Anderson DR, Sweeney DJ, Williams TA (1994) Introduction to statistics: concepts and applications, 3rd edn. West Publishing, New York

Barrett EM (1963) The California oyster industry. Calif Dep Fish Game Fish Bull 123:1-103

Buchan LAJ, Padilla DK (2000) Predicting the likelihood of Eurasion watermillfoil presence in lakes, macrophyte monitoring tool. Ecol Appl 10(5):1442-1455

Carlton JT (1979) History, biogeography, and ecology of the introduced marine and estuarine invertebrates of the Pacific coast of North America. PhD dissertation, University of California, Davis

Carlton JT (1992) Introduced marine and estuarine mollusks of North America: an end-of-the-20th-century perspective. J Shellfish Res 11:489-505

Carlton JT (2001) Introduced species in US coastal waters: environmental impacts and management priorities. Pew Oceans Commission, Arlington, VA

Carlton JT, Cohen AN (1998) Periwinkles' progress: the Atlantic snail Littorina saxatilis (Mollusca: Gastropoda) establishes a colony of a Pacific shore. Veliger 41:333-338

Cohen AN, Carlton JT (1995) Nonindigenous aquatic species in a United States estuary: a case study of the biological invasions of the San Francisco Bay and Delta. US Fish and Wildlife Service, Washington, DC

Elton CS (1958) The ecology of invasions by animals and plants. Methuen, London

Eno NC, Clark RA, Sanderson WG (1997) Non-native marine species in British waters: a review and directory. Joint Nature Conservation Committee, Peterborough

Fielding AH, Bell JF (1997) A review of methods for the assessment of prediction errors in conservation/absence models. Environ Conserv 24(1):38-49

Frappier B, Eckert RT (2003) Utilizing the USDA PLANTS database to predict exotic woody plant invasiveness in New Hampshire. For Ecol Manag 185:207-215

Goodwin BJ, McAllister AJ, Fahrig L (1998) Predicting invasiveness of plant species based on biological information. Conserv Biol 13:422-426

Grosholz E (2002) Ecological and evolutionary consequences of coastal invasions. Trends Ecol Evol 17:22-27

Hopkins DR (1986) Atlas of the distribution and abundance of common benthic species in San Francisco Bay. California US Geological Survey Waters Resources Investigations Report 86-4003, Denver, CO, p 1-228

Hurme E, Mönkkönen M, Nikula A, Reunanen P, Heikkinen T, Ukkola M (2005) Building and evaluating predictive occupancy models for the Siberian flying squirrel using forest planning data. For Ecol Manag 216:241-256

Ingersoll E (1881) The oyster-industry. In: Goode GB (ed) The history and present condition of the fishery industries. Tenth Census of the United States. US Department of the Interior, Washington, DC

Jeschke JM, Strayer D (2005) Invasion success of vertebrates in Europe and North America. Proc Natl Acad Sci USA 102:7198-7202

Johannesson K (1988) The paradox of Rockall: Why is a brooding gastropod (Littorina saxatilis) more widespread than one having a planktonic larval dispersal stage (Littorina littorea)? Mar Biol 99:507-513

Kennish MJ (1990) Estuarine ecology. Vol II. Biological aspects. CRC Press, Boca Raton, FL

Kochiss JM (1974) Oystering from New York to Boston. Mystic Seaport, Middletown, CT

Kolar CS, Lodge DM (2001) Progress in invasion biology: predicting invaders. Trends Ecol Evol 16:199-204

Kolar CS, Lodge DM (2002) Ecological predictions and risk assessment for alien fishes in North America. Science 298:1233-1236

Lee CE, Remfert JL, Gelembiuk GW (2003) Evolution of physiological tolerance and performance during freshwater invasions. Integr Comp Biol 43:439-449

Lockwood JL, Cassey P, Blackburn T (2005) The role of propagule pressure in explaining species invasions. Trends Ecol Evol 20:223-228

Lonsdale WM (1999) Global patterns of plant invasions and the concept of invisibility. Ecology 80:1522-1536

Mack RN, Simberloff D, Lonsdale WM, Evans H, Clout M, Bazzaz, FA (2000) Biotic invasions: causes, epidemiology, global consequences, and control. Ecol Appl 10:689-710

Miller AW (2000) Assessing the importance of biological attributes for invasion success: eastern oyster (Crassostrea virginica) introductions and associated molluscan invasions of Pacific and Atlantic coastal systems. DEnv dissertation, University of California, Los Angeles

Miller AW, Chang AL, Cosentino-Manning N, Ruiz GM (2004) A new record and eradication of the Northern Atlantic alga Ascophyllum nodosom (Phaeophyceae) from San Francisco Bay, California, USA. J Phycol 40:1028-1031

Pimentel D, Lach L, Zuniga D, Morrison D (2000) Environmental and economic costs of nonindigenous species in the United States. Bioscience 50:53-65

Race MS (1982) Competitive displacement and predation between introduced and native mud snails. Oecologia 54:337-347

Reichard S, Hamilton CW (1997) Predicting invasions of woody plants introduced to North America. Conserv Biol 11:193-203

Rejmánek M, Richardson DM (1996) What attributes make some plant species more invasive? Ecology 77:1655-1661

Roy J, Navas L, Sonie L (1991) Invasion by annual bromes grasses: a case study challenging the homoclime approach 
to invasions. In: Groves RH, Di Castri F (eds) Biogeography of Mediterranean invasions. Cambridge University Press, Cambridge, p 205-221

Ruesink JL (2005) Global analysis of factors affecting the outcome of freshwater fish introductions. Conserv Biol 19: 1883-1893

Ruiz GM, Carlton JT (2003) Invasion vectors: a conceptual framework for management. In: Ruiz GM, Carlton JT (eds) Invasive species: vectors and management strategies. Island Press, Covelo, CA, p 457-504

Ruiz GM, Hewitt C (2003) Toward understanding patterns of coastal marine invasions: a prospectus. In: Leppakoski E, Gollasch S, Olenin S (eds) Invasive aquatic species of Europe: distribution, impacts and management. Kluwer Academic, Dordrecht, p 529-547

Ruiz GM, Fofonoff P, Carlton JT, Wonham MJ, Hines AH (2000) Invasions of coastal marine communities in North America: apparent patterns, processes, and biases. Annu Rev Ecol Syst 31:481-531

Editorial responsibility: Lisa Levin (Contributing Editor), La Jolla, California, USA
SAS (2002) SAS/STAT software, Version 9.1. SAS System for Microsoft Windows. SAS Institute, Cary, NC

Shoener TW, Spiller DA (1995) Effect of predator and area invasion: an experiment with island spiders. Science 267:1811-1813

Simberloff D (2001) Case study 3.23. Invasiveness cannot be reliably predicted. In: Wittenberg $\mathrm{R}$, Cock MJW (eds) Invasive alien species: a toolkit of best prevention and management practices. CABI, CAB International, Wallingford, p 100

Smith CS, Lonsdale WM, Fortune J (1999) When to ignore advice: invasion predictions and decision theory. Biol Invasions 1:89-96

Williamson M (1999) Invasions. Ecography 22:5-12

Williamson MH, Fitter A (1996) The characters of successful invaders. Biol Conserv 78:163-170

Winkley HW (1888) Mollusca found in the oyster beds of Cocagne, N. B., Bedeque and Summerside, P.E.I. Bull Nat Hist Soc NB 7:69-71

Submitted: March 2, 2006; Accepted: July 31, 2006

Proofs received from author(s): February 12, 2007 